\title{
Immune-Enhancing Diets: What is the Final Answer?
}

\author{
D. Dante Yeh $^{1}$ - Daren Heyland ${ }^{2,3}$
}

Published online: 13 May 2016

(C) Springer International Publishing AG 2016

\begin{abstract}
Supplementation of certain micronutrients to standard nutrition therapy in pharmacological doses can modulate the host immunologic response. The three most extensively studied: arginine, glutamine, and omega-3 fatty acids ("fish oils"). While animal studies are encouraging, human clinical trials arrive at conflicting conclusions for multiple reasons, mainly related to heterogeneity in patient selection, concentration and combination of agents, dose, route, and timing and administration. Glutamine should not be given to patients with multi-organ (especially renal) failure and arginine should be avoided in septic shock. Enteral glutamine may be beneficial in burn and trauma patients. Larger, higher-quality studies are required before strong recommendations can be made.
\end{abstract}

Keywords Immunonutrition $\cdot$ Glutamine $\cdot$ Arginine $\cdot$ Fish oil

\section{Introduction}

Nutrition therapy has become increasingly recognized as a key component of optimal care of the critically injured

This article is part of the Topical Collection on Nutrition After Severe Trauma

D. Dante Yeh

dyeh2@mgh.harvard.edu

1 Department of Surgery, Division of Trauma, Emergency Surgery, and Surgical Critical Care, Massachusetts General Hospital, 165 Cambridge St. \#810, Boston, MA 02114, USA

2 Clinical Evaluation Research Unit, Kingston General Hospital, Angada 476 Stuart St., Kingston, ON K7L 2V7, Canada

3 Department of Critical Care Medicine, Queen's University, Kingston, ON, Canada patient. Accumulating evidence demonstrate that providing early and sufficient nutrition is associated with improvements in important outcomes such as infections, ventilator days, intensive care unit (ICU) length of stay, hospital days, discharge location, physical recovery, and mortality $[1,2]$. Unfortunately, international surveys have also revealed that ICU patients, particularly surgical and trauma patients often do not receive the full amount of prescribed macronutrients (calories and protein) [3]. For example, two large observational studies reported that trauma patients in general and patients with traumatic brain injury (TBI) received slightly over half of their required calories and protein [3, 4]. Severe trauma imposes significant stress upon the patient and causes an acute phase marked by catabolism, oxidative stress, and immune system dysfunction [5-8]. Dysregulated processes are believed to predispose the patient to complications such as infectious morbidity, multi-organ failure, and death. These complications can be reduced by early and optimal of artificial nutrition [1,2].

Since the 1980s, it has long been recognized that supplementation of certain micronutrients to standard nutrition therapy in pharmacological doses can modulate the host immunologic response. Termed "immunomodulating agents", "immunonutrition", "pharmaconutrition", or "nutritional pharmacology" [9, 10], these micronutrients may be added to standard formula as an enrichment or may be administered separately as a medication. Because of the aforementioned difficulties in providing adequate nutrition (both enterally and parenterally), the latter approach may be preferable in order to ensure consistency and adequacy of delivery. While many nutrients have been considered for supplementation, this review will focus on the three most extensively studied: arginine, glutamine, and omega-3 fatty acids ("fish oils"). 


\section{Glutamine}

Glutamine is the most abundant amino acid and is the main fuel source for rapidly dividing cells such as enterocytes, macrophages, and lymphocytes. Numerous animal and human studies have implicated glutamine in the normal function of the immune system, whether by mediating $\mathrm{T}$ cell immunity or acting as an antioxidant. Other proposed key functions of glutamine include acting as a nitrogen shuttle, participating in glucose metabolism, inducing heat shock proteins, or stimulating autophagy [11]. During states of health, glutamine is a nonessential amino acid and can be synthesized by the body. However, low levels of glutamine have been observed during critical illness and trauma $[12,13]$ and are associated with increased mortality $[14,15]$; thus, glutamine had come to be referred to as "conditionally essential" [11, 16], though the exact origin of the concept is obscure. The association led many to hypothesize that administering exogenous glutamine, parenterally or enterally, to restore glutamine to "normal" levels during critical illness may improve clinical outcomes $[15,17]$. Indeed, animal models of hemorrhagic shock demonstrate that glutamine supplementation can attenuate the impairment of intestinal blood flow, potentially preserving mucosal integrity [18], while peritonitis models have shown that glutamine enhances peritoneal bacterial clearance [19] as well as neutrophil function through increased production of reactive oxygen intermediates [20]. Based on encouraging observational studies and meta-analyses of smaller randomized trials [21], two large, well-designed and adequate powered multicenter trials have recently been conducted.

\section{Reducing Deaths Due to Oxidative Stress (REDOXS) [22•]}

The REDOXS trial randomized 1223 mechanically ventilated adults with multi-organ failure to receive glutamine (enteral and parenteral) supplementation, antioxidants, both, or placebo in a $2 \times 2$ factorial design. Trauma patients comprised less than $3 \%$ of all subjects and patients with severe traumatic brain injury (TBI) were specifically excluded. The study was conducted in 40 ICUs in Europe, Canada, and the USA. Contrary to expectation, the patients receiving glutamine had a significant increase in hospital and 6-month mortality. Furthermore, there was no effect of glutamine on infectious complications or organ failure. Antioxidants had no effect on the primary endpoint of 28-day mortality or any other secondary endpoint. Several important points must be made. In this study, the majority of patients were in shock and the harm was mostly observed in patients with renal failure [23]. Additionally, the dose of parenteral and enteral glutamine was relatively high $(30 \mathrm{~g} /$ day enteral glutamine and $0.35 \mathrm{~g} / \mathrm{kg}$ ideal body weight per day), over twice the previously recommended doses. This should be contrasted with prior studies showing benefit, which were performed in hemodynamically stable patients without organ failure at lower doses $(0.3-0.5 \mathrm{~g} /$ $\mathrm{kg} /$ day). Thus, while the results of the REDOXS study clearly identify patients who should not receive glutamine, many questions remain regarding which patients may potentially benefit.

\section{Metaplus [24]}

The Metaplus trial was conducted in 14 ICUs across Europe and randomized 301 adult patients on mechanical ventilation to an enteral formula enriched with glutamine, selenium, and fish oils or to a high-protein control formula. Both groups received the same amounts of calories and protein. There was no difference in the primary endpoint of new infections. Similar to the REDOXS study, the Metaplus trial demonstrated an increase in 6-month mortality in the medical patients receiving the enriched formula.

After the publication of the REDOXS and Metaplus trials, some have begun to question the hypothesis that low glutamine levels cause worse outcomes. It may be possible that low glutamine levels are, in fact, an adaptive stress response and supplementation may be counter-productive [25]. This is analogous to the familiar concept of "permissive hypotension" in trauma patients $[26,27]$. In a few short years, the enthusiasm for glutamine has been greatly tempered and some have heralded an "end of an era" [28]. Much remain unknown, as it has been observed that low glutamine levels are inconsistent and widely variable, having little correlation with severity of illness markers such as the commonly used APACHE II score [14]. Less than a third of critically ill patients are actually glutamine-deficient $[15,29]$. Interestingly, about $15 \%$ of patients may have baseline high levels of glutamine, a state which is also associated with worse outcomes [14]. Thus, one explanation of the divergent findings of recent studies may be that without measurement of actual glutamine levels, some patients with high glutamine levels may have received supplementation. A trend towards higher mortality in patients with high baseline glutamine levels treated with supplemental glutamine was observed in the Metaplus trial.

One potential concern about glutamine supplementation in trauma (specifically TBI) patients is the fact that glutamate is excitotoxic and may exacerbate edema, worsening secondary brain injury [30, 31]. While some have been hesitant to prescribe glutamine to brain injured patients for fear of elevating brain glutamate levels. These concerns have not yet been borne out thus far, even with relatively high doses of continuous glutamine infusion [32, 33].

Meta-analysis of randomized trials has concluded that enteral supplementation with glutamine in heterogeneous critically ill patient populations is not associated with improvements in mortality, infectious complications, or ICU length of stay [34]. The most recent recommendations from the Society of Critical Care Medicine (SCCM) and the Canadian Practice Guidelines recommend against routine enteral or parenteral glutamine supplementation in critically ill patients [35••]. Clinical trials enrolling exclusively trauma patients are 
plagued with methodological flaws such as small sample size, surrogate outcomes, heterogeneous populations, inconsistent nutrition delivery, varying glutamine delivery routes, etc. [36-44] We statistically aggregated all the randomized trials of glutamine in exclusively trauma patients. Glutamine has not been shown to improve mortality or length of stay in trauma patients but is associated with a trend towards reduced infectious complications. (Fig. 1a-c) In patients with burn injury, meta-analysis of glutamine supplementation in burns demonstrates decreased hospital mortality, infectious complications, specifically Gram-negative bacteremia, and hospital
LOS (Fig. 2a, b). Thus, to summarize the state-of-the-art evidence, glutamine supplementation should not be given to critically ill patients in multi-organ failure. For burn and trauma patients, moderate dose enteral glutamine $(<0.5 \mathrm{~g} / \mathrm{kg} / \mathrm{day})$ may be considered after resuscitation is complete [29] but more research is needed to confirm these estimates of treatment effect. The RE-ENERGIZE trial is a large-scale, multinational, multicenter randomized trial that aims to enroll 2700 burn injured patients to evaluate the effect of enteral glutamine on 6 month mortality in this unique patient population and is currently enrolling patients (clinicaltrials.gov ID

a

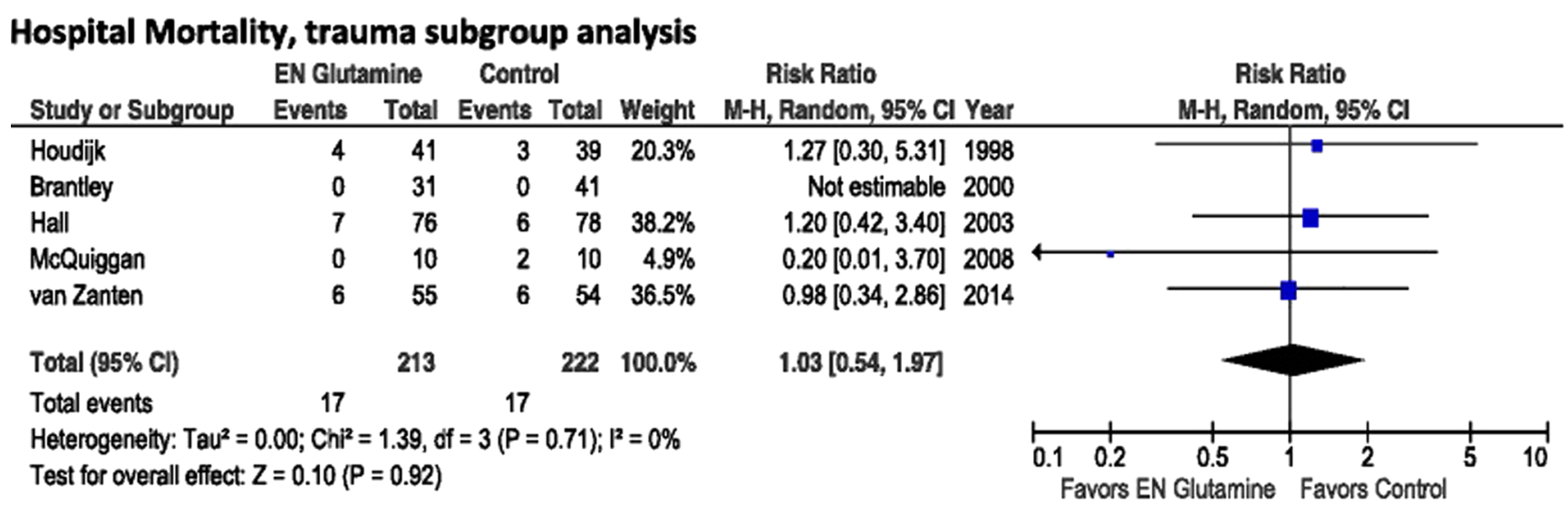

b

Infectious complications, trauma subgroup analysis

EN glutamine Control Risk Ratio

\begin{tabular}{|c|c|c|c|c|c|c|c|c|}
\hline Study or Subgroup & Events & Total & Events & Total & Weight & M-H, Random, 95\% Cl Year & M-H, Random, $95 \% \mathrm{Cl}$ & \\
\hline Houdijk & 20 & 35 & 26 & 37 & $40.5 \%$ & $0.81[0.57,1.16] 1998$ & & \\
\hline van Zanten & 32 & 55 & 36 & 54 & $59.5 \%$ & $0.87[0.65,1.17] 2014$ & 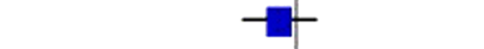 & \\
\hline Total $(95 \% \mathrm{Cl})$ & & 90 & & 91 & $100.0 \%$ & $0.85[0.68,1.06]$ & & \\
\hline Total events & 52 & & 62 & & & & & \\
\hline $\begin{array}{l}\text { Heterogeneity: Tau }= \\
\text { Test for overall effect: }\end{array}$ & $\begin{array}{l}.00 ; \mathrm{Ch}^{2} \\
=1.43(\mathrm{P}\end{array}$ & $\begin{array}{l}0.09, d \\
=0.15)\end{array}$ & $f=1\langle P=$ & 0.76 ; ; & $=0 \%$ & & 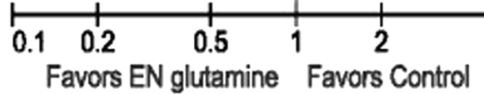 & $5 \quad 10$ \\
\hline
\end{tabular}

C

Hospital LOS, trauma subgroup analysis

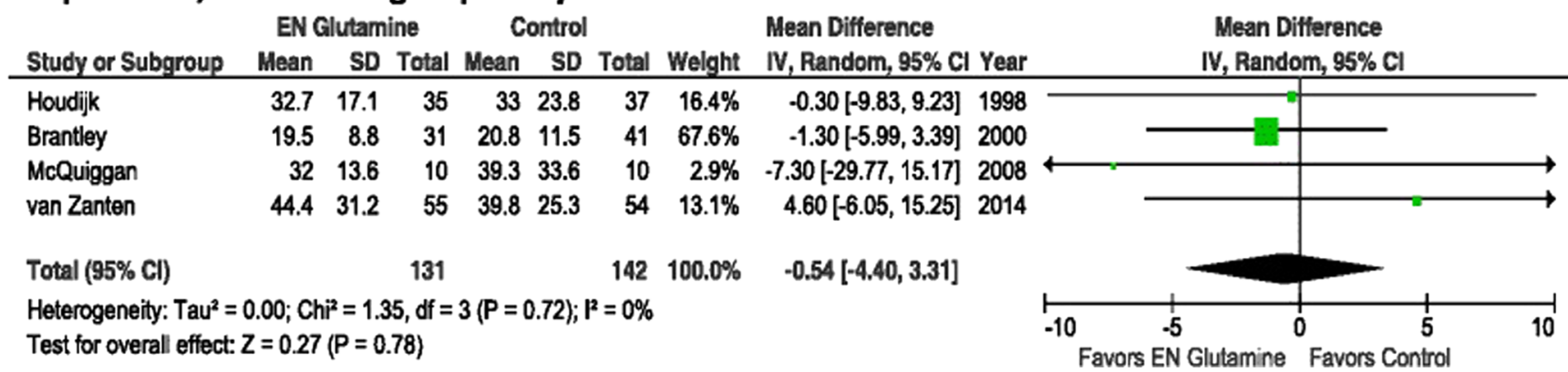

Fig. 1 a Meta-analysis of glutamine trials, trauma subgroup, and mortality b Meta-analysis of glutamine trials, trauma subgroup, infectious complications c Meta-analysis of glutamine trials, trauma subgroup, and hospital LOS 
a

Hospital Mortality, burns subgroup analysis

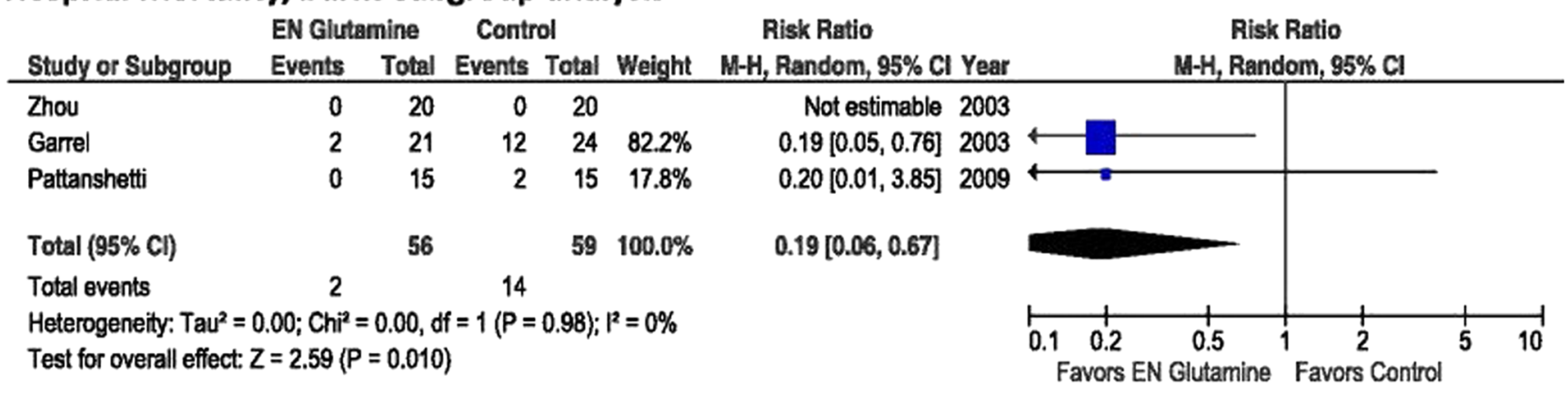

b

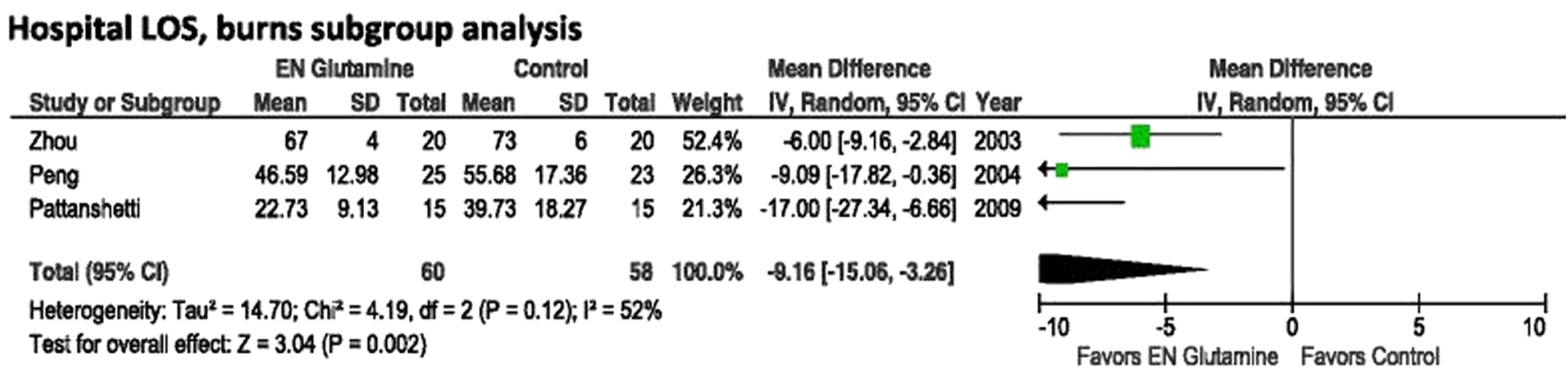

Fig. 2 a Meta-analysis of glutamine trials, burns subgroup, and mortality b Meta-analysis of glutamine trials, burns subgroup, and hospital LOS

\#NCT00985205). A similar mortality-based trial of glutamine in trauma patients is warranted.

\section{Arginine}

Arginine stimulates the release of growth factor, prolactin, and insulin. As a precursor for hydroxyproline (and thus collagen), arginine is necessary for tissue repair and wound healing [45]. In experimental animal models, arginine has been shown to enhance macrophage phagocytic activity and reactive oxygen species production by neutrophils [46, 47]. Studies have shown that serum arginine levels are likewise depressed soon after major trauma and burns, mainly from increased degradation with unchanged de novo synthesis [48-51]. Thus, arginine, like glutamine, has been similarly labeled as "conditionally essential" or "semiessential" $[52,53]$ and many have tried to demonstrate benefit from supplementing arginine in critically ill patients. However, arginine is a precursor for nitric oxide, a potent vasodilator, and arginine supplementation in animal models has shown increased nitric oxide production with subsequent loss of vascular tone and hypotension $[54,55]$. This finding has also been found in human clinical trials [56-58]. These detrimental effects were not seen in stable populations.

Interestingly, arginine may have a role in neuroprotection after traumatic brain injury through reduction of excitotoxicity and attenuation of mitochondrial dysfunction [59]. Despite the long-standing interest in arginine as a potential pharmaconutrient and a wealth of animal experiments [60], relatively few clinical trials have been performed exclusively in trauma patients [61].

The 2015 update to the Canadian Clinical Practice guidelines meta-analyzed five level 1 studies and 22 level 2 studies and concluded by recommending against routine arginine supplementation in critically ill patients, particularly those with sepsis [62]. Meta-analysis of the subgroup of trauma patients found no overall evidence of benefit or harm regarding mortality or infectious complications [62]. (Figure 3a-b) However, the most recent 2016 SCCM recommendations provide a weak recommendation for arginine supplementation in severe trauma, based on very low quality evidence $[35 \cdot \bullet]$. This recommendation is based on a meta-analysis (which did not find any benefit of argininecontaining formulas over standard formula) [62], a single RCT of 20 patients [37], and expert consensus review.

\section{Fish Oils}

The omega-3 fatty acids eicosapenaenoic acid (EPA) and docosahexaenoic acid (DHA), the so-called "fish oils" or poly-unsaturated long-chain fatty acids (PUFAs), are considered less inflammatory than the commonly used omega- 6 fatty acids through alterations in cell membrane structure and function, signaling pathways, and gene expression. 


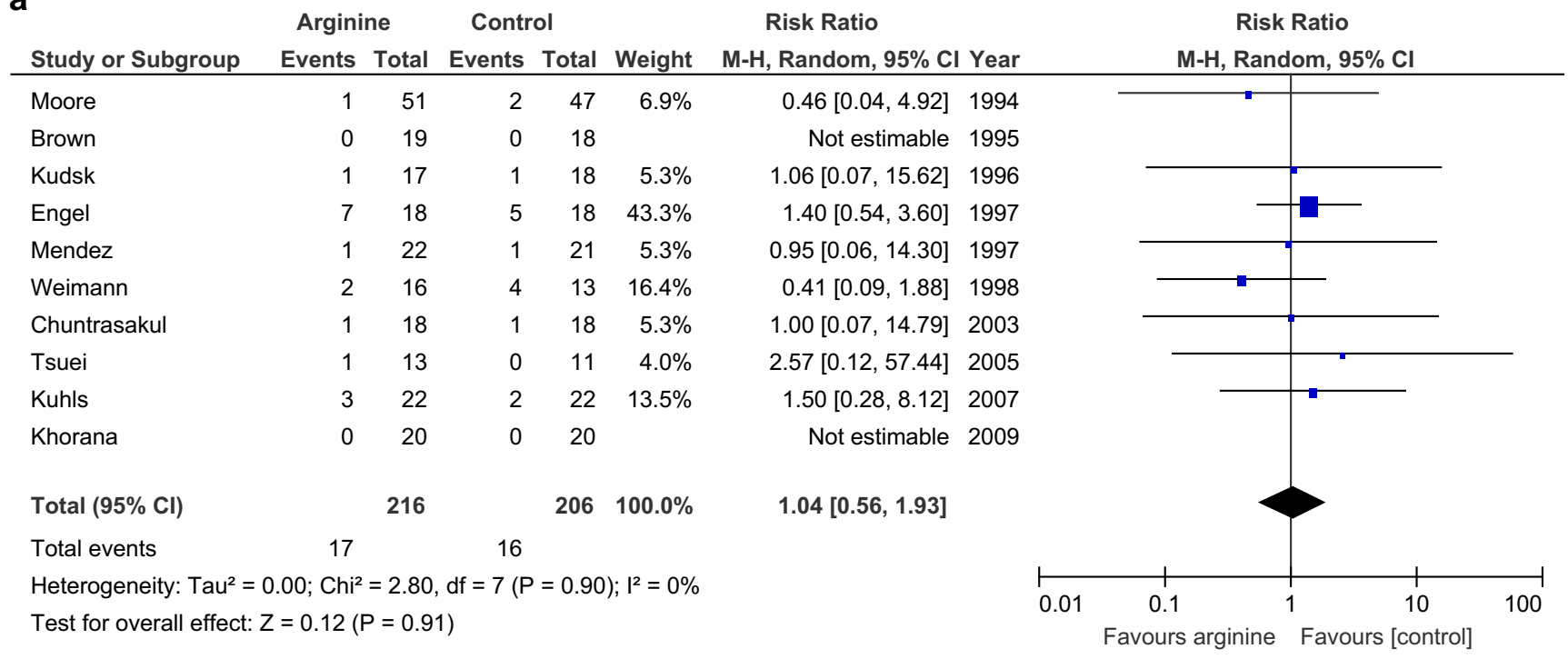

b

\begin{tabular}{|c|c|c|c|c|c|c|c|c|c|c|c|}
\hline \multirow[b]{2}{*}{ Study or Subgroup } & \multicolumn{2}{|c|}{ Arginine } & \multicolumn{2}{|c|}{ Control } & \multicolumn{3}{|c|}{ Risk Ratio } & \multirow{2}{*}{\multicolumn{4}{|c|}{$\begin{array}{c}\text { Risk Ratio } \\
\text { M-H, Random, } 95 \% \mathrm{Cl} \\
\end{array}$}} \\
\hline & Events & Total & Events & Total & Weight & M-H, Random, $95 \% \mathrm{Cl}$ & Year & & & & \\
\hline Moore & 9 & 51 & 10 & 47 & $16.3 \%$ & $0.83[0.37,1.86]$ & 1994 & & 4 & & \\
\hline Brown & 3 & 19 & 10 & 18 & $11.9 \%$ & $0.28[0.09,0.87]$ & 1995 & & & & \\
\hline Kudsk & 5 & 16 & 11 & 17 & $16.3 \%$ & $0.48[0.22,1.08]$ & 1996 & & & & \\
\hline Mendez & 19 & 22 & 12 & 21 & $23.6 \%$ & $1.51[1.01,2.27]$ & 1997 & & & - & \\
\hline Engel & 6 & 18 & 5 & 18 & $13.5 \%$ & $1.20[0.45,3.23]$ & 1997 & & & & \\
\hline Tsuei & 8 & 13 & 6 & 11 & $18.4 \%$ & $1.13[0.57,2.25]$ & 2005 & & & & \\
\hline Total $(95 \% \mathrm{Cl})$ & & 139 & & 132 & $100.0 \%$ & $0.86[0.52,1.42]$ & & & & & \\
\hline Total events & 50 & & 54 & & & & & & & & \\
\hline \multicolumn{8}{|c|}{ Heterogeneity: $\mathrm{Tau}^{2}=0.24 ; \mathrm{Chi}^{2}=13.74, \mathrm{df}=5(\mathrm{P}=0.02) ; \mathrm{I}^{2}=64 \%$} & 0.01 & 0.1 & & 100 \\
\hline
\end{tabular}

Fig. 3 a Meta-analysis of arginine trials, trauma subgroup, and mortality b meta-analysis of arginine trials, trauma subgroup, and infectious complications

Initial trials demonstrated that patients with septic or acute respiratory distress syndrome (ARDS) supplemented with these "fish oils" benefited in pulmonary neutrophil recruitment, alveolar cytokine levels, gas exchange, mechanical ventilation requirements, new-onset organ failure, and ICU length of stay [63-65], though some did not show any benefit [66].

\section{OMEGA Trial [67•]}

The OMEGA trial was sponsored by the National Heart, Lung, and Blood Institute ARDS Clinical Trials Network and randomized 272 adults at 44 hospitals in the USA to receive enteral nutrition supplemented with fish oils and antioxidants or an isocaloric control. The study was stopped early for futility for the primary endpoint of 28-day ventilator-free days. Importantly, there were concerning trends noted in some secondary endpoints. Specifically, patients receiving fish oils had higher 60-day hospital mortality, fewer ICU-free days, fewer nonpulmonary organ failure-free days, and higher number of days with diarrhea.

Immune system effects aside, fish oils such as DHA may have a role in traumatic brain injury (TBI) and spinal cord injury through other mechanisms such as reduction of excitotoxcity, mitigation of neuronal cell death, and repair of nervous damage [68-71]. Animal studies are encouraging, but there have been no controlled clinical trials performed to date [72-76]. Human experience is limited to only two case reports [77, 78]. Thus, fish oils may have a place in the treatment of TBI, though there is not sufficient evidence to recommend routine use. At this time, based on conflicting evidence, there is no recommendation for routine enteral fish-oil supplementation in ICU patients with or without ARDS [35••]. Trials focusing specifically on trauma patients have failed to find any benefit of fish-oil supplementation [79]. 


\section{Limitations of Existing Studies}

With few exceptions, existing studies of immune-modulating nutrients are plagued by methodological flaws. The vast majority are limited in sample size and underpowered to detect differences in clinically meaningful outcomes. There is little consistency between studies in patient population, duration and timing of treatment, measured outcomes, and composition and concentration of pharmaconutrients used. Furthermore, there is wide variance in the timing of enteral nutrition, use of parenteral nutrition, and adequacy of macronutrient delivery. Therefore, metaanalyses must be interpreted with caution. Indeed, there is a bewildering array of meta-analyses, of varying quality, which attempt to combine the randomized trials according to patient population and route [80-86]. All have commented upon the high degree of heterogeneity. Not surprisingly, these metaanalyses have arrived at conflicting conclusions regarding efficacy and effect size. To combine critically ill and trauma patients together is implicitly stating that a 73 -year-old woman on chronic steroids for rheumatoid arthritis in multi-organ failure from urosepsis would have the same response to glutamine or arginine as a 22-year-old healthy man with severe brain injury, pulmonary contusions, and multiple fractured extremities or a 40 year-old man with $80 \%$ burns and inhalational injury. Trauma and sepsis have been historically considered to be similar, due to the common phenotype of the systemic inflammatory response syndrome (SIRS). Recently, however, a new definition of sepsis, "Sepsis-3", has been derived and validated using large databases and sophisticated statistical methods which divorces SIRS from sepsis [87]. This lends further weight to the argument that sepsis and trauma are distinct and separate phenomena which should be treated differently. Even after separating trauma patients from the rest of the critically ill, it is questionable to aggregate all injured patients (penetrating, blunt, TBI, burns, etc.) into one group. To group all trauma patients together into a single trial is analogous to enrolling patients with melanoma, lung, breast, bone, and thyroid malignancies into a single "cancer" study.

Many studies investigated proprietary "immune-enhancing formulas" and therefore it is impossible to discern the contributions of individual components such as glutamine, arginine, fish oils, nucleotides, antioxidants, trace elements, butyrate and difficult to combine their results for meta-analysis $[57,88,89]$. These proprietary formulas have differing concentrations of multiple components, making meta-analysis difficult, if not impossible. (Table 1) Interactions between components may be important, as illustrated by evidence that arginine supplementation causes increased plasma glutamine levels [90]. Adding further to the confusion, in some studies the two arms did not receive comparable calories/protein and the control group was administered a pro-inflammatory formula, skewing the results in favor of the intervention group [91]. The majority of trials did not actually measure baseline serum levels of glutamine, arginine, or fish oils or the effect of treatment. Therefore, it remains unclear whether or not the enrolled subjects even required supplementation or had the intended increase in serum levels. Future trials should consider supplementing only patients with documented low glutamine levels, as only about $30 \%$ of critically ill patients are actually hypoglutaminemic at admission and high glutamine levels have also been associated with increased mortality [14].

Finally, one must consider the overall improvements in critical care that have resulted in approximately $1 \%$ decrease in mortality per year over the past few decades [92]. With changes such as lung-protective ventilation, bundles for prevention of central line-associated bloodstream infections and ventilator-associated pneumonia, early ambulation, daily interruption of sedation and spontaneous breathing trials, tighter glycemic control, fluid restriction, and restrictive blood transfusion, the immunomodulatory effects of micronutrients may no longer be as important as they once were a decade ago. For example, a time-sequential analysis of glutamine studies
Table 1 Immunonutrition products and comparison (per $1000 \mathrm{kcal})$

\begin{tabular}{llllll}
\hline Product & $\mathrm{kcal} / \mathrm{mL}$ & Arginine $(\mathrm{g})$ & EPA/DHA $(\mathrm{g})$ & Glutamine $(\mathrm{g})$ & Nucleotides \\
\hline AlitraQ $^{\mathrm{a}}$ & 1.0 & 4.4 & 0 & 15.5 & 0 \\
Crucial $^{\mathrm{c}}$ & 1.5 & 10 & 3.6 & 0 & 0 \\
Immun-Aid $^{\mathrm{d}}$ & 1.0 & 14 & 0 & 12 & 1.0 \\
Impact $^{\mathrm{b}}$ & 1.0 & 12.5 & 1.7 & 0 & 1.2 \\
${\text { Impact } 1.5^{\mathrm{b}}}^{\mathrm{a}}$ & 1.5 & 12.5 & 1.5 & 0 & 1.2 \\
Optimental $^{\mathrm{a}}$ & 1.0 & 5.5 & 3.26 & 0 & 0 \\
Perative $^{\mathrm{a}}$ & 1.3 & 6 & 0 & 0 & 0 \\
${\text { Pivot } 1.5^{\mathrm{a}}}^{\mathrm{S}}$ & 1.5 & 8.6 & 2.6 & 0 & 0 \\
Stresson Multi-fibre $^{\mathrm{c}}$ & 1.25 & 7.12 & 0.88 & 10.4 & 0 \\
\hline Ross Products & & & & & \\
${ }^{\mathrm{b}}$ Novartis Nutrition & & & & & \\
${ }^{\mathrm{c}}$ Nestle Clinical Nutrition & & & & &
\end{tabular}


demonstrated that only trials performed prior to 2003 reported positive effects, whereas more recent studies reporting no benefit [93].

\section{Conclusions}

The provision of specific micronutrients in pharmacologic doses for the purposes of modulating the immune response is an area of ongoing active investigation. Agents such as glutamine, arginine, and fish oils are neither panaceas nor universal venoms. As with all interventions, timing, drug dose, and route of administration are important considerations and appropriate patient selection is paramount. The same intervention may be beneficial in one patient and harmful in another. We must guard against inappropriate extrapolations, lest we throw the baby out with the bath water $[58,94]$. At present, the existing evidence does not support the routine supplementation of arginine or fish oils in severely injured, critically ill patients [35••]. Routine glutamine supplementation during hemodynamic instability (especially in the setting of renal insufficiency) is strongly discouraged, though enteral glutamine may still be considered for burn patients. Much remain unknown and additional research is required to further clarify which particular patient populations will benefit from supplementation by which route with which micronutrient at which dose for what duration of treatment.

\section{Compliance with Ethical Standards}

Conflict of Interest Dr. Yeh reports that he is a consultant with Covidien and has received an educational research grant from Nestle. Dr. Heyland reports grants from Nestle Healthcare Institute, outside the submitted work.

Human and Animal Rights and Informed Consent This article does not contain any studies with human or animal subjects performed by any of the authors.

\section{References}

Papers of particular interest, published recently, have been highlighted as:

- Of importance

•. Of major importance

1. Wei $X$ et al. The association between nutritional adequacy and longterm outcomes in critically Ill patients requiring prolonged mechanical ventilation: a multicenter cohort study. Crit Care Med. 2015;43(8):1569-79.

2. Heyland DK. Should we PERMIT systematic underfeeding in all intensive care unit patients? Integrating the results of the PERMIT study in Our clinical practice guidelines. JPEN J Parenter Enteral Nutr. 2016;40(2):156-8.

3. Wade $\mathrm{CE}$ et al. Evaluation of nutrition deficits in adult and elderly trauma patients. JPEN J Parenter Enteral Nutr. 2015;39(4):449-55.

4. Chapple LA et al. Nutrition support practices in critically ill headinjured patients: a global perspective. Crit Care. 2016;20(1):6.

5. Wilson RF, Tyburski JG. Metabolic responses and nutritional therapy in patients with severe head injuries. J Head Trauma Rehabil. 1998;13(1):11-27.

6. Brandi LS et al. Energy expenditure and severity of injury and illness indices in multiple trauma patients. Crit Care Med. 1999;27(12):2684-9.

7. Marik PE, Flemmer M. The immune response to surgery and trauma: implications for treatment. J Trauma Acute Care Surg. 2012;73(4):801-8.

8. Askanazi $\mathrm{J}$ et al. Muscle and plasma amino acids after injury: hypocaloric glucose vs. amino acid infusion. Ann Surg. 1980;191(4):465-72.

9. Alexander JW. Nutritional pharmacology in surgical patients. Am J Surg. 2002;183(4):349-52.

10. Jones NE, Heyland DK. Pharmaconutrition: a new emerging paradigm. Curr Opin Gastroenterol. 2008;24(2):215-22.

11. Bongers T, Griffiths RD, McArdle A. Exogenous glutamine: the clinical evidence. Crit Care Med. 2007;35(9 Suppl):S545-52.

12. Gore DC, Jahoor F. Glutamine kinetics in burn patients. Comparison with hormonally induced stress in volunteers. Arch Surg. 1994;129(12):1318-23.

13. Jackson $\mathrm{NC}$ et al. The metabolic consequences of critical illness: acute effects on glutamine and protein metabolism. Am J Physiol. 1999;276(1 Pt 1):E163-70.

14. Rodas PC et al. Glutamine and glutathione at ICU admission in relation to outcome. Clin Sci (Lond). 2012;122(12):591-7.

15. Oudemans-van Straaten HM et al. Plasma glutamine depletion and patient outcome in acute ICU admissions. Intensive Care Med. 2001;27(1):84-90.

16. Rosenthal MD et al. Evolving paradigms in the nutritional support of critically ill surgical patients. Curr Probl Surg. 2015;52(4):147-82.

17. Wernerman J. Role of glutamine supplementation in critically ill patients. Curr Opin Anaesthesiol. 2008;21(2):155-9.

18. Flynn Jr WJ, Gosche JR, Garrison RN. Intestinal blood flow is restored with glutamine or glucose suffusion after hemorrhage. J Surg Res. 1992;52(5):499-504.

19. Furukawa $\mathrm{S}$ et al. Glutamine-enriched enteral diet enhances bacterial clearance in protected bacterial peritonitis, regardless of glutamine form. JPEN J Parenter Enteral Nutr. 1997;21(4):208-14.

20. Saito H, Furukawa S, Matsuda T. Glutamine as an immunoenhancing nutrient. JPEN J Parenter Enteral Nutr. 1999;23(5 Suppl):S59-61.

21. Novak F et al. Glutamine supplementation in serious illness: a systematic review of the evidence. Crit Care Med. 2002;30(9):2022-9.

22. Heyland D et al. A randomized trial of glutamine and antioxidants in critically ill patients. N Engl J Med. 2013;368(16):1489-97. The REDOX trial was the largest and most rigorous trial of glutamine in critically ill patients. This landmark trial demonstrated no benefit of glutamine and antioxidant supplementation and showed a trend towards increased mortality.

23. Heyland DK et al. Glutamine and antioxidants in the critically ill patient: a post hoc analysis of a large-scale randomized trial. JPEN J Parenter Enteral Nutr. 2015;39(4):401-9.

24. van Zanten AR et al. High-protein enteral nutrition enriched with immune-modulating nutrients vs standard high-protein enteral nutrition and nosocomial infections in the ICU: a randomized clinical trial. JAMA. 2014;312(5):514-24.

25. Van den Berghe G. Low glutamine levels during critical illnessadaptive or maladaptive? N Engl J Med. 2013;368(16):1549-50. 
26. Bickell WH et al. Immediate versus delayed fluid resuscitation for hypotensive patients with penetrating torso injuries. N Engl J Med. 1994;331(17):1105-9.

27. Schreiber, M.A., et al., A controlled resuscitation strategy is feasible and safe in hypotensive trauma patients: results of a prospective randomized pilot trial. J Trauma Acute Care Surg, 2015. 78(4): p. 687-95; discussion 695-7.

28. van Zanten AR, Hofman Z, Heyland DK. Consequences of the REDOXS and METAPLUS trials: the end of an era of glutamine and antioxidant supplementation for critically Ill patients? JPEN J Parenter Enteral Nutr. 2015;39(8):890-2.

29. Heyland DK, Dhaliwal R. Role of glutamine supplementation in critical illness given the results of the REDOXS study. JPEN J Parenter Enteral Nutr. 2013;37(4):442-3.

30. Kempski $\mathrm{O}$ et al. Intravenous glutamate enhances edema formation after a freezing lesion. Adv Neurol. 1990;52:219-23.

31. Yi JH, Hazell AS. Excitotoxic mechanisms and the role of astrocytic glutamate transporters in traumatic brain injury. Neurochem Int. 2006;48(5):394-403.

32. Nageli $\mathrm{M}$ et al. Prolonged continuous intravenous infusion of the dipeptide L-alanine- L-glutamine significantly increases plasma glutamine and alanine without elevating brain glutamate in patients with severe traumatic brain injury. Crit Care. 2014;18(4):R139.

33. Berg A et al. Intravenous glutamine supplementation to head trauma patients leaves cerebral glutamate concentration unaffected. Intensive Care Med. 2006;32(11):1741-6.

34. van Zanten AR et al. Enteral glutamine supplementation in critically ill patients: a systematic review and meta-analysis. Crit Care. 2015; 19:294.

35.• Taylor BE et al. Guidelines for the provision and assessment of nutrition support therapy in the adult critically ill patient: Society of Critical Care Medicine (SCCM) and American Society for Parenteral and Enteral Nutrition (A.S.P.E.N.). Crit Care Med. 2016;44(2):390-438. This recently published set of guidelines represents a synthesis of the best available evidence in critically ill adults.

36. Grintescu IM et al. The influence of parenteral glutamine supplementation on glucose homeostasis in critically ill polytrauma patients - a randomized-controlled clinical study. Clin Nutr. 2015;34(3):377-82.

37. de Arruda Falcao IS, de Aguilar-Nascimento JE. Benefits of early enteral nutrition with glutamine and probiotics in brain injury patients. Clin Sci (Lond). 2004;106(3):287-92.

38. Eroglu A. The effect of intravenous alanyl-glutamine supplementation on plasma glutathione levels in intensive care unit trauma patients receiving enteral nutrition: the results of a randomized controlled trial. Anesth Analg. 2009;109(2):502-5.

39. Houdijk AP et al. Randomised trial of glutamine-enriched enteral nutrition on infectious morbidity in patients with multiple trauma. Lancet. 1998;352(9130):772-6.

40. Perez-Barcena $\mathrm{J}$ et al. A randomized trial of intravenous glutamine supplementation in trauma ICU patients. Intensive Care Med. 2014;40(4):539-47.

41. Wischmeyer PE et al. Glutamine administration reduces Gramnegative bacteremia in severely burned patients: a prospective, randomized, double-blind trial versus isonitrogenous control. Crit Care Med. 2001;29(11):2075-80.

42. Jensen GL et al. A double-blind, prospective, randomized study of glutamine-enriched compared with standard peptide-based feeding in critically ill patients. Am J Clin Nutr. 1996;64(4):615-21.

43. Mendez, C., et al., Effects of an immune-enhancing diet in critically injured patients. J Trauma, 1997. 42(5): p. 933-40; discussion $940-1$

44. Lorenz, K.J., R. Schallert, and V. Daniel, Immunonutrition - the influence of early postoperative glutamine supplementation in enteral/parenteral nutrition on immune response, wound healing and length of hospital stay in multiple trauma patients and patients after extensive surgery. GMS Interdiscip Plast Reconstr Surg DGPW, 2015. 4: p. Doc15.

45. Zaloga GP et al. Arginine: mediator or modulator of sepsis? Nutr Clin Pract. 2004;19(3):201-15.

46. Yeh CL et al. Effects of arginine-containing total parenteral nutrition on $\mathrm{N}$ balance and phagocytic activity in rats undergoing a partial gastrectomy. Br J Nutr. 2005;93(2):267-72.

47. Muhling $\mathrm{J}$ et al. Alterations in neutrophil (PMN) free intracellular alpha-keto acid profiles and immune functions induced by L-alanyl-L-glutamine, arginine or taurine. Amino Acids. 2005;29(3): 289-300.

48. Chiarla C, Giovannini I, Siegel JH. Plasma arginine correlations in trauma and sepsis. Amino Acids. 2006;30(1):81-6.

49. Yu YM et al. Plasma arginine and leucine kinetics and urea production rates in burn patients. Metabolism. 1995;44(5):659-66.

50. $\mathrm{Yu} \mathrm{YM}$ et al. Arginine and ornithine kinetics in severely burned patients: increased rate of arginine disposal. Am J Physiol Endocrinol Metab. 2001;280(3):E509-17.

51. Jeevanandam $\mathrm{M}$ et al. Effect of major trauma on plasma free amino acid concentrations in geriatric patients. Am J Clin Nutr. 1990;51(6):1040-5.

52. Zhou M, Martindale RG. Arginine in the critical care setting. J Nutr. 2007;137(6 Suppl 2):1687S-92S.

53. Davis JS, Anstey NM. Is plasma arginine concentration decreased in patients with sepsis? A systematic review and meta-analysis. Crit Care Med. 2011;39(2):380-5.

54. Bruins $\mathrm{MJ}$ et al. L-arginine supplementation in hyperdynamic endotoxemic pigs: effect on nitric oxide synthesis by the different organs. Crit Care Med. 2002;30(3):508-17.

55. Lorente JA et al. Modulation of systemic hemodynamics by exogenous L-arginine in normal and bacteremic sheep. Crit Care Med. 1999;27(11):2474-9.

56. Bertolini $\mathrm{G}$ et al. Early enteral immunonutrition in patients with severe sepsis: results of an interim analysis of a randomized multicentre clinical trial. Intensive Care Med. 2003;29(5):834-40.

57. Bower RH et al. Early enteral administration of a formula (Impact) supplemented with arginine, nucleotides, and fish oil in intensive care unit patients: results of a multicenter, prospective, randomized, clinical trial. Crit Care Med. 1995;23(3):436-49.

58. Heyland DK, Samis A. Does immunonutrition in patients with sepsis do more harm than good? Intensive Care Med. 2003;29(5):669-71.

59. Chiu LS et al. The neuroprotective potential of arginine-rich peptides for the acute treatment of traumatic brain injury. Expert Rev Neurother. 2016;16(4):361-3.

60. Popovic PJ, Zeh 3rd HJ, Ochoa JB. Arginine and immunity. J Nutr. 2007;137(6 Suppl 2):1681S-6S.

61. Yan $\mathrm{H}$ et al. Effects of early enteral arginine supplementation on resuscitation of severe burn patients. Burns. 2007;33(2):179-84.

62. http://criticalcarenutrition.com/docs/CPGs $\% 202015 / 4.1 \mathrm{a} \%$ 202015.pdf (Accessed April 30, 2016).

63. Gadek JE et al. Effect of enteral feeding with eicosapentaenoic acid, gamma-linolenic acid, and antioxidants in patients with acute respiratory distress syndrome. Enteral Nutrition in ARDS Study Group. Crit Care Med. 1999;27(8):1409-20.

64. Pontes-Arruda A, Aragao AM, Albuquerque JD. Effects of enteral feeding with eicosapentaenoic acid, gamma-linolenic acid, and antioxidants in mechanically ventilated patients with severe sepsis and septic shock. Crit Care Med. 2006;34(9):2325-33.

65. Singer $\mathrm{P}$ et al. Benefit of an enteral diet enriched with eicosapentaenoic acid and gamma-linolenic acid in ventilated patients with acute lung injury. Crit Care Med. 2006;34(4):1033-8.

66. Grau-Carmona $\mathrm{T}$ et al. Effect of an enteral diet enriched with eicosapentaenoic acid, gamma-linolenic acid and anti-oxidants on 
the outcome of mechanically ventilated, critically ill, septic patients. Clin Nutr. 2011;30(5):578-84.

67. Rice TW et al. Enteral omega-3 fatty acid, gamma-linolenic acid, and antioxidant supplementation in acute lung injury. JAMA. 2011;306(14):1574-81. The OMEGA trial was the largest and most rigorous trial of fish-oils in adults with acute respiratory distress syndrome (ARDS). It was terminated early for futility.

68. Hasadsri L et al. Omega-3 fatty acids as a putative treatment for traumatic brain injury. J Neurotrauma. 2013;30(11):897-906.

69. Barrett EC, McBurney MI, Ciappio ED. Omega-3 fatty acid supplementation as a potential therapeutic aid for the recovery from mild traumatic brain injury/concussion. Adv Nutr. 2014;5(3): 268-77.

70. Mills JD et al. Omega-3 fatty acid supplementation and reduction of traumatic axonal injury in a rodent head injury model. J Neurosurg. 2011;114(1):77-84.

71. Michael-Titus AT, Priestley JV. Omega-3 fatty acids and traumatic neurological injury: from neuroprotection to neuroplasticity? Trends Neurosci. 2014;37(1):30-8.

72. Bailes JE, Mills JD. Docosahexaenoic acid reduces traumatic axonal injury in a rodent head injury model. J Neurotrauma. 2010;27(9):1617-24.

73. Begum $\mathrm{G}$ et al. Docosahexaenoic acid reduces ER stress and abnormal protein accumulation and improves neuronal function following traumatic brain injury. J Neurosci. 2014;34(10):3743-55.

74. Wu A, Ying Z, Gomez-Pinilla F. The salutary effects of DHA dietary supplementation on cognition, neuroplasticity, and membrane homeostasis after brain trauma. J Neurotrauma. 2011;28(10): 2113-22.

75. King VR et al. Omega-3 fatty acids improve recovery, whereas omega- 6 fatty acids worsen outcome, after spinal cord injury in the adult rat. J Neurosci. 2006;26(17):4672-80.

76. Huang WL et al. A combination of intravenous and dietary docosahexaenoic acid significantly improves outcome after spinal cord injury. Brain. 2007;130(Pt 11):3004-19.

77. Lewis M, Ghassemi P, Hibbeln J. Therapeutic use of omega-3 fatty acids in severe head trauma. Am J Emerg Med. 2013;31(1): 273 e5-8.

78. Roberts L et al. Surviving a mine explosion. J Am Coll Surg. 2008;207(2):276-83.

79. Kagan I et al. Preemptive enteral nutrition enriched with eicosapentaenoic acid, gamma-linolenic acid and antioxidants in severe multiple trauma: a prospective, randomized, double-blind study. Intensive Care Med. 2015;41(3):460-9.

80. Heyland DK et al. Should immunonutrition become routine in critically ill patients? A systematic review of the evidence. JAMA. 2001;286(8):944-53.
81. Beale RJ, Bryg DJ, Bihari DJ. Immunonutrition in the critically ill: a systematic review of clinical outcome. Crit Care Med. 1999;27(12):2799-805.

82. Bollhalder L et al. A systematic literature review and meta-analysis of randomized clinical trials of parenteral glutamine supplementation. Clin Nutr. 2013;32(2):213-23.

83. Marik PE, Zaloga GP. Immunonutrition in critically ill patients: a systematic review and analysis of the literature. Intensive Care Med. 2008;34(11):1980-90.

84. Marik PE, Zaloga GP. Immunonutrition in high-risk surgical patients: a systematic review and analysis of the literature. JPEN J Parenter Enteral Nutr. 2010;34(4):378-86.

85. Montejo JC et al. Immunonutrition in the intensive care unit. A systematic review and consensus statement. Clin Nutr. 2003;22(3):221-33.

86. Palmer AJ et al. The role of omega-3 fatty acid supplemented parenteral nutrition in critical illness in adults: a systematic review and meta-analysis. Crit Care Med. 2013;41(1):307-16.

87. Singer $\mathrm{M}$ et al. The Third International Consensus Definitions for Sepsis and Septic Shock (Sepsis-3). JAMA. 2016;315(8):801-10.

88. Beale RJ et al. Early enteral supplementation with key pharmaconutrients improves sequential organ failure assessment score in critically ill patients with sepsis: outcome of a randomized, controlled, double-blind trial. Crit Care Med. 2008;36(1):131-44.

89. Kudsk, K.A., et al., A randomized trial of isonitrogenous enteral diets after severe trauma. An immune-enhancing diet reduces septic complications. Ann Surg, 1996. 224(4): p. 531-40; discussion $540-3$.

90. Loi $\mathrm{C}$ et al. Increasing plasma glutamine in postoperative patients fed an arginine-rich immune-enhancing diet - a pharmacokinetic randomized controlled study. Crit Care Med. 2009;37(2):501-9.

91. Wiedemann HP. Fish oil is not the fix for acute lung injury. Crit Care Med. 2011;39(7):1829-30.

92. Kaukonen KM et al. Mortality related to severe sepsis and septic shock among critically ill patients in Australia and New Zealand, 2000-2012. JAMA. 2014;311(13):1308-16.

93. Fadda $\mathrm{V}$ et al. Temporal trend of short-term mortality in severely ill patients receiving parenteral glutamine supplementation. Clin Nutr. 2013;32(3):492-3.

94. Wischmeyer P. Glutamine supplementation in parenteral nutrition and intensive care unit patients: are we throwing the baby Out with the bathwater? JPEN J Parenter Enteral Nutr. 2015;39(8):893-7.

95. Krenitsky, J., Immunonutrition-fact, fancy or folly? Practical Gastroenterology, 2006. May. 